\title{
Penerapan Metode AHP pada Penentuan Sales Terbaik Studi Kasus: PT. Sampoerna Telekomunikasi Indonesia
}

\author{
Imron \\ Program Studi Administrasi Bisnis \\ Universitas Bina Sarana Informatika \\ e-mail: imron.imr@bsi.ac.id
}

Cara Sitasi: Imron, I. (2019). Penerapan Metode AHP pada Penentuan Sales Terbaik Studi Kasus: PT Sampoerna Telekomunikasi Indonesia. Jurnal Teknik Komputer, 127-134. doi:10.31294/jtk.v4i2

\begin{abstract}
Competition in various business sectors between companies cannot be avoided. One of the supporters of the success of various aspects of the work of the company is human resources, which is one of the assets of the company that runs the wheels of the business movement. An example of an aspect that always becomes competition between companies is the sale of a product created by each company. One of the supporters of the success of selling a product in the company is sales. The number of products sold depends on how the sales can market the product. So it requires talented sales people to attract new customers, increase product sales, and increase customer satisfaction. Therefore leaders must be able to assess the capabilities of salespeople in marketing the company's products. So that leaders can determine which sales can be maintained and which ones need to be replaced. AHP is one of the tools (processes) in decision making. This procedure is so powerful that it has been widely applied in important decision making. AHP can be relied on, because in AHP a priority is composed of various choices that can be in the form of criteria that have been previously decomposed (structure) first, so that priority setting is based on a structured (hierarchical) process and makes sense
\end{abstract}

Keywords: SPK, AHP, Sales, Sampoerna

\section{PENDAHULUAN}

Persaingan dalam berbagai sektor bisnis antar perusahaan tidak dapat dihindari. Salah satu pendukung keberhasilan berbagai aspek kerja dari perusahaan adalah sumber daya manusia yang merupakan salah satu aset perusahaan yang menjalankan roda pergerakan bisnis tersebut. Contoh aspek yang selalu menjadi persaingan antar perusahaan adalah penjualan suatu produk yang diciptakan masing-masing perusahaan.

Salah satu pendukung keberhasilan penjualan suatu produk di perusahaan adalah sales, termasuk penjualan layanan telekomunikasi seluler Net1 pada PT. Sampoerna Telekomunikasi Indonesia. Net1 yang merupakan salah satu layanan telekomunikasi seluler yang menggunakan teknologi 4G LTE yang berada di frekuensi $450 \mathrm{MHz}$, yang saat ini digemari masyarakat baik di kota maupun pedesaan untuk mengakses internet dengan mudah dan cepat.

Banyaknya produk yang terjual tergantung bagaimana sales dapat memasarkan produk tersebut. Maka diperlukan sales yang berbakat agar dapat menarik customer baru, meningkatkan penjualan produk, dan meningkatkan kepuasaan kepada customer. Oleh karena itu pemimpin harus bisa menilai kemampuan yang dimiliki para sales dalam memasarkan produk - produk perusahaan.
Sehingga pemimpin dapat menentukan mana sales yang dapat dipertahankan dan mana yang perlu digantikan. Melihat kenyataan tersebut, penulis membuat sebuah sistem pendukung keputusan pemilihan sales terbaik dengan metode AHP.

Menurut Yuliani dalam Amalia dan Utami (2018:183)"Selain itu metode AHP memiliki kelebihan dalam mengambil suatu keputusan dengan cara membandingkan secara berpasangan setiap kriteria yang dimiliki oleh suatu permasalahan sehingga didapat suatu bobot nilai dari kepentingan tiap kriteria-kriteria yang ada".

Pada PT. Sampoerna Telekomunikasi Indonesia pemberian reward kepada sales hanya berdasarkan aspek penjualan dan aspek lainnya tidak mempengaruhi penilaian dan penilaian tidak menggunakan suatu metode.

AHP merupakan salah satu alat bantu (proses) dalam pengambilan keputusan yang dikembangkan oleh Thomas L Saaty pada tahuhn 70an. Prosedur ini begitu powerfull sehingga sudah diaplikasikan secara luas dalam pengambilan keputusan yang penting. AHP dapat diandalkan, karena dalam AHP suatu prioritas disusun dari berbagai pilihan yang dapat berupa kriteria yang sebelumnya telah didekomposisi (struktur) terlebih dahulu, sehingga penetapan prioritas didasarkan pada suatu proses yang terstruktur (hierarki) dan masuk 
akal. Jadi pada intinya AHP membantu memecahkan persoalan yang kompleks dengan menyusun suatu hirarki kriteria, dinilai secara subjektif oleh pihak yang berkepentingan lalu menarik berbagai pertimbangan guna mengembangkan bobot atau prioritas (kesimpulan)

\section{METODOLOGI PENELITIAN}

\section{A. Prosedur AHP}

Terdapat tiga prinsip utama dalam pemecahan masalah dalam AHP menurut Saaty, yaitu: Decompositiot, Comparative Judgement, dan Logical Concistency. Secara garis besar prosedur AHP meliputi tahapan sebagai berikut:

1) Dekomposisi masalah;

Dekomposisi masalah adalah langkah dimana suatu tujuan (Goal) yang telah ditetapkan selanjutnya diuraikan secara sistematis kedalam struktur yang menyusun rangkaian sistem hingga tujuan dapat dicapai secara rasional. Dengan kata lain, sutu tujuan (goal) yang utuh, didekomposisi (dipecahkan) kedalam unsur penyusunnya. Apabila unsur tersebut merupakan kriteria yang dipilih seyogyanya mencakup semua aspek penting terkait dengan tujuan yang ingin dicapai. Namun kita harus tetap mempertimbangkan agar kriteria yang dipulih benarbenar mempunyai makna bagi pengambilan keputusan dan tidak mempunyai makna atau pengertian yang yang sama, shingga walaupun kriteria pilihan hanya sedikit namun mempunyai makna yang besar terhadap tujuan yang ingin dicapai. Setelah kriteria ditetapkan, selanjutnya adalah menentukan alternatif atau pilihan penyelesaian masalah. Sehingga apabila digambarkan kedalam bentuk bagan hierarki seperti ditunjukkan pada Gambar berikut:

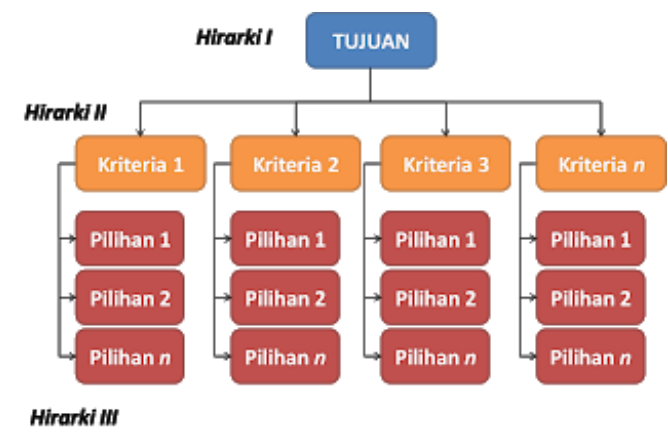

Sumber: Saaty (2008)

Gambar 1. Hirarki Metode AHP

2) Penilaian/pembobotan untuk membandingkan elemen-elemen;

Prosedur penilaian perbandingan berpasangan dalam AHP, mengacu pada skor penilaian yang telah dikembangkan oleh Saaty, sebagai berikut:
Tabel 1. Pembobotan Perbandingan

\begin{tabular}{ll}
\hline $\begin{array}{l}\text { Intensitas } \\
\text { Pentingnya }\end{array}$ & Definisi \\
\hline $\mathbf{1}$ & $\begin{array}{l}\text { Kedua elemen/alternatif sama pentingnya } \\
\text { (equal) }\end{array}$ \\
\hline $\mathbf{3}$ & $\begin{array}{l}\text { Eleman A sedikit lebih esensial dari elemen B } \\
\text { (moderate) }\end{array}$ \\
\hline $\mathbf{5}$ & \begin{tabular}{l} 
Elemen A lebih esensial dari elemen B (strong) \\
\hline $\mathbf{7}$ \\
(very strong)
\end{tabular} \\
\hline $\mathbf{9}$ & $\begin{array}{l}\text { Elemen A mutlak lebih esensial dari elemen B } \\
\text { (very strong) }\end{array}$ \\
\hline $\mathbf{2 , 4 , 6 , 8}$ & $\begin{array}{l}\text { Nilai nilai Antara dua perimbangan yang } \\
\text { berdekatan }\end{array}$ \\
\hline Sumberan Ba
\end{tabular}

Sumber: Saaty (2008)

3) Penyusunan matriks dan Uji consistensi;

Langkah pertama: adalah menyatukan pendapat dari beberapa kuisioner, jika kuisioner diisi oleh pakar, maka kita akan menyatukan pendapat para pakar kedangan menggunakan persamaan rata-rata geometri:

$$
\begin{aligned}
& G M=\sqrt[n]{ }\left(X_{1}\right)\left(X_{2}\right) \ldots . .\left(X_{n}\right) \\
\text { Dimana: } & \\
\text { GM } & =\text { Geometric Mean } \\
\text { X1 } & =\text { Pakar ke-1 } \\
\text { X2 } & =\text { Pakar ke-2 } \\
\text { Xn } & =\text { Pakar ke- } n
\end{aligned}
$$

Langkah kedua: menyusun matriks perbandingan, sebagai berikut:

Tabel 2. Matriks Perbandingan

\begin{tabular}{lcccc}
\hline $\begin{array}{l}\text { Kriteria/ } \\
\text { Alternatif }\end{array}$ & $\mathbf{1}$ & $\mathbf{2}$ & $\mathbf{3}$ & $\mathbf{N}$ \\
\hline $\mathbf{1}$ & 1 & GM12 & GM13 & GM1N \\
\hline $\mathbf{2}$ & GM21 & 1 & GM23 & GM2N \\
\hline $\mathbf{3}$ & GM31 & GM32 & 1 & GM3N \\
\hline $\mathbf{4}$ & GM41 & GM42 & GM43 & 1 \\
\hline Sumber: Saaty (2008) & & &
\end{tabular}

Langkah ketiga: uji konsistensi terlebih dahulu dilakukan dengan menyusun tingkat kepentingan relatif pada masing-masing kriteria atau alternatif yang dinyatakan sebagai bobot relatif ternormalisasi (normalized relative weight). Bobot relatif yang dinormalkan ini merupakan suatu bobot nilai relatif untuk masing-masing elemen pada setiap kolom yang dibandingkan dengan jumlah masing-masing elemen: Tabel 3. Uji Konsistensi

$\begin{array}{lllll}\text { Kriteria/ } & 1 & 2 & 3 & \text { N } \\ \text { Alternatif } & & & & \end{array}$

\begin{tabular}{lcccc}
\hline $\mathbf{1}$ & 1 & GM12 & GM13 & GM1N \\
\hline $\mathbf{2}$ & GM21 & 1 & GM23 & GM2N \\
\hline $\mathbf{3}$ & GM31 & GM32 & 1 & GM3N \\
\hline $\mathbf{n}$ & GMn1 & GMn2 & GMn3 & 1 \\
\hline$\sum$ & GM11+ & GM12+ & GM13+ & GM1n+ \\
n1 & n2 & n3 & ni \\
\hline Sumber: Saaty (2008) & & & \\
\hline
\end{tabular}


Maka bobot relatif ternormalisasi adalah:

Tabel 4. Bobot relatif ternormalisasi

\begin{tabular}{lcccc}
\hline $\begin{array}{l}\text { Kritera/Alt } \\
\text { ernatif }\end{array}$ & $\mathbf{1}$ & $\mathbf{2}$ & $\mathbf{3}$ & $\mathbf{N}$ \\
\hline $\mathbf{1}$ & $1 / \mathrm{GM} 11-$ & GM12/G & GM13/G & GM1n/G \\
& n1 & M12-n2 & M13-n3 & M13-n3 \\
\hline $\mathbf{2}$ & GM21/G & 1 GM12- & GM23/G & GM2n/G \\
& M11-n1 & n2 & M13-n3 & M13-n3 \\
\hline $\mathbf{3}$ & GM21/G & GM32/G & 1 GM13- & GM3n/G \\
& M11-n1 & M12-n2 & n3 & M13-n3 \\
\hline $\mathbf{n}$ & GM21/G & GMn2/G & GM12/G & 1 GM13- \\
& M11-n1 & M12-n2 & M12-n2 & n3 \\
\hline
\end{tabular}

Sumber: Saaty (2008)

Selanjutnya tentukan nilai CI (consistency Index) dengan persamaan:

$$
C I=\frac{\lambda \text { maksimum }-n}{n-1}
$$

Dimana CI adalah indeks konsistensi dan Lambda maksimum adalah nilai eigen terbesar dari matriks berordo $n$.

Nilai eigen terbesar adalah jumlah hasil kali perkalian jumlah kolom dengan eigen vaktor utaman. Sehingga dapat diperoleh dengan persamaan:

$$
\lambda \text { maksimum }=\left(\sum \mathrm{GM}_{11-\mathrm{n} 1} \times \bar{X} 1\right)+\cdots+\left(\sum \mathrm{GM}_{1 \mathrm{n}-\mathrm{ni}} \times \bar{X} n\right)
$$

Setelah memperoleh nilai lambda maksismum selanjutnya dapoat ditentukan nilai CI. Apabila nilai CI bernilai nol (0) berarti matriks konsisten. Jika nilai CI yag diperoleh lebih besar dari 0 (CI>0) selanjutnya diuji batas ketidak konsistenan yang diterapkan oleh Saaty. Pengujian diukur dengan menggunakan Consistency Ratio (CR), yaitu nilai indeks, atau perbandingan antara CI dan RI:

$$
C R=\frac{C I}{R I}
$$

Nilai RI yang digunakan sesuai denan ordo n matriks. Apabila CR matriks lebih kecil $10 \%(0,1)$ berarti bahwa ketidak konsistenan pendapat masing dianggap dapat diterima.

4) Penetapan prioritas pada masing-masing hirarki, dan sintesis prioritas.

Penetapan prioritas pada tiap-tiap hierarki dilakukan melalui proses Iterasi (perkalian matriks). Langkah pertama yang dilakukan adalah merubah bentuk fraksi nilai-nilai pembiobotan kedalam bentuk desimal. Agar lebih mudah difahami, kita menggunakan salah satu contoh data hasil penilaian salah seorang pakar seperti contoh berikut:

Tabel 5. Penetapan Prioritas

\begin{tabular}{lcccc}
\hline & Kekuatan & $\begin{array}{c}\text { Kelemaha } \\
\mathbf{n}\end{array}$ & $\begin{array}{c}\text { Peluan } \\
\mathbf{g}\end{array}$ & $\begin{array}{c}\text { Ancama } \\
\mathbf{n}\end{array}$ \\
\hline Kekuatan & $1 / 1$ & $1 / 2$ & $3 / 1$ & $4 / 1$ \\
\hline $\begin{array}{l}\text { Kelemaha } \\
\text { n }\end{array}$ & $2 / 1$ & $1 / 1$ & $1 / 3$ & $3 / 1$ \\
\hline Peluang & $1 / 3$ & $3 / 1$ & $1 / 1$ & $2 / 3$ \\
\hline Ancaman & $1 / 4$ & $1 / 3$ & $3 / 2$ & $1 / 1$ \\
\hline
\end{tabular}

Sumber: Saaty (2008)

6) Pengambilan/penetapan keputusan.

Penarikan kesimpulan dilakukan dengan mengakumulasi nilai/ bobot global yang merupakan nilai sensitivitas masing-masing elemen. Seperti pada contoh diatas, maka kesimpulan nutamanya adlah aspek kekuatan perlu diperhatikan karena merupakan prioritas utama, kemudian aspek kelemahan, ancaman dan peluang..

\section{HASIL DAN PEMBAHASAN}

\section{A. Mendefinisakan Masalah}

Tahapan pendefinisian masalah dipakai dalam hal memecah masalah yang besar serta menyederhanakan permasalahan tersebut menjadi permasalahan yang lebih kecil, dan digambarkan dalam suatu bentuk hirarki. Dalam hirarki ini dibuat menjadi 3 bagian yaitu tujuan, kriteria dan alternatif. Kriteria terdiri dari penjualan, absensi, attitude, penampilan dan kerjasama tim. Alternatif nya terdiri dari Rudianto, Chaerul Uman dan Baso Nurdiansyah.

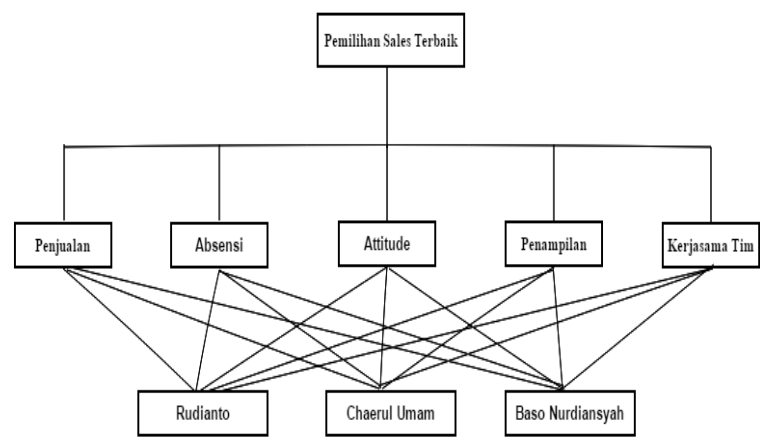

Sumber : Imron Imron (2018)

Gambar 2

Hirarki Pemilihan Sales Terbaik

\section{B. Matriks Perbandingan Berpasangan}

Dalam matriks perbandingan dengan berpasangan dimana data diperoleh dari responden yang berjumlah 16 orang, maka perlu dibuat rata-rata untuk masing-masing elemen perbandingan dengan menggunakan rumus Geometric Mean Theory dengan cara mengalikan semua elemen matriks banding yang sama letaknya kemudian diakar pangkatkan sesuai dengan jumlah responden sehingga didapatkan matriks perhitungan rata-rata untuk masing-masing elemen.

$$
a_{w}=\sqrt[n]{a_{1} x a_{2} x a_{3} x \ldots x a_{n}}
$$

\section{Sintesis}

Sintesis dilakukan sebanyak jumlah matriks perbandingan yang telah dibuat. Dalam penelitian ini sintesis yang ada meliputi:

\section{1) Sintesis level 1 berdasarkan kriteria utama}


Tabel 6. Nilai Rata-rata Kriteria Utama

\begin{tabular}{|c|c|c|c|c|c|c|}
\hline Kriteria & $\begin{array}{l}\text { Penjua } \\
\text { lan }\end{array}$ & $\begin{array}{c}\text { Abse } \\
\text { nsi }\end{array}$ & $\begin{array}{l}\text { Attit } \\
\text { ude }\end{array}$ & $\begin{array}{c}\text { Penam } \\
\text { pilan }\end{array}$ & $\begin{array}{l}\text { Kerjasa } \\
\text { ma TIM }\end{array}$ & $\begin{array}{l}\text { Rata- } \\
\text { Rata }\end{array}$ \\
\hline $\begin{array}{l}\text { Penjual } \\
\text { an }\end{array}$ & 0,30 & 0,49 & 0,38 & 0,27 & 0,18 & 0,31 \\
\hline Absensi & 0,07 & 0,11 & 0,19 & 0,09 & 0,13 & 0,12 \\
\hline Attitude & 0,21 & 0,15 & 0,26 & 0,40 & 0,41 & 0,29 \\
\hline $\begin{array}{l}\text { Penamp } \\
\text { ilan }\end{array}$ & 0,07 & 0,07 & 0,04 & 0,06 & 0,07 & 0,06 \\
\hline $\begin{array}{l}\text { Kerjasa } \\
\text { ma TIM }\end{array}$ & 0,36 & 0,18 & 0,13 & 0.18 & 0,21 & 0,21 \\
\hline & & & & & $\begin{array}{l}\text { Eigen } \\
\text { Vector }\end{array}$ & 1,00 \\
\hline \multicolumn{7}{|c|}{ Sumber : Imron Imron (2018) } \\
\hline \multicolumn{7}{|c|}{$\begin{array}{c}\text { 2) Sintesis level } 2 \text { berdasarkan kriteria penjualan } \\
\text { Tabel } 7 \text { Nilai Rata-rata Penjualan }\end{array}$} \\
\hline Kriteria & Rudi: & into & $\begin{array}{l}\text { Chaerul } \\
\text { Umam }\end{array}$ & $\begin{array}{r}\text { B } \\
\text { Nurdi }\end{array}$ & $\begin{array}{l}\text { so } \\
\text { nsyah }\end{array}$ & $\begin{array}{l}\text { ata- } \\
\text { ata }\end{array}$ \\
\hline Rudianto & 0,6 & & 0,67 & & & 69 \\
\hline $\begin{array}{l}\text { Chaerul } \\
\text { Umam }\end{array}$ & 0,1 & & 0,15 & & & 14 \\
\hline $\begin{array}{l}\text { Baso } \\
\text { Nurdiansy } \\
\text { ah }\end{array}$ & 0,1 & & 0,18 & & & 16 \\
\hline
\end{tabular}

Sumber : Imron Imron (2018)

3) Sintesis level 2 berdasarkan kriteria absensi

Tabel 8. Nilai Rata-rata Absensi

\begin{tabular}{lcccc}
\hline Kriteria & Rudianto & $\begin{array}{c}\text { Chaerul } \\
\text { Umam }\end{array}$ & $\begin{array}{c}\text { Baso } \\
\text { Nurdiansyah }\end{array}$ & $\begin{array}{c}\text { Rata- } \\
\text { Rata }\end{array}$ \\
\hline Rudianto & 0,49 & 0,54 & 0,46 & 0,50 \\
\hline $\begin{array}{l}\text { Chaerul } \\
\text { Umam }\end{array}$ & 0,19 & 0,21 & 0,24 & 0,22 \\
\hline $\begin{array}{l}\text { Baso } \\
\text { Nurdiansyah }\end{array}$ & 0,31 & 0,25 & 0,29 & 0,29 \\
\hline & & & Eigen Vector & 1,00 \\
\hline
\end{tabular}

Sumber : Imron Imron (2018)

4) Sintesis level 2 berdasarkan attitude

\begin{tabular}{lcccc}
\multicolumn{5}{c}{ Tabel 9 Nilai Rata-rata Attitude } \\
\hline Kriteria & Rudianto & $\begin{array}{c}\text { Chaerul } \\
\text { Umam }\end{array}$ & $\begin{array}{c}\text { Baso } \\
\text { Nurdiansyah }\end{array}$ & $\begin{array}{c}\text { Rata- } \\
\text { Rata }\end{array}$ \\
\hline Rudianto & 0,51 & 0,53 & 0,49 & 0,51 \\
\hline $\begin{array}{l}\text { Chaerul } \\
\text { Umam }\end{array}$ & 0,17 & 0,18 & 0,20 & 0,18 \\
\hline $\begin{array}{l}\text { Baso } \\
\text { Nurdiansyah }\end{array}$ & 0,33 & 0,29 & 0,32 & 0,31 \\
\hline
\end{tabular}

Sumber : Imron Imron (2018)

5) Sintesis level 2 berdasarkan penampilan

Tabel 10. Nilai Rata-rata Penampilan

\begin{tabular}{lcccc}
\hline Kriteria & Rudianto & $\begin{array}{c}\text { Chaerul } \\
\text { Umam }\end{array}$ & $\begin{array}{c}\text { Baso } \\
\text { Nurdiansyah }\end{array}$ & $\begin{array}{c}\text { Rata- } \\
\text { Rata }\end{array}$ \\
\hline Rudianto & 0,30 & 0,29 & 0,27 & 0,28 \\
\hline $\begin{array}{l}\text { Chaerul } \\
\text { Umam }\end{array}$ & 0,20 & 0,20 & 0,20 & 0,20 \\
\hline $\begin{array}{l}\text { Baso } \\
\text { Nurdiansyah }\end{array}$ & 0,49 & 0,52 & 0,53 & 0,51 \\
\hline & & \multicolumn{3}{c}{ Eigen Vector } \\
\hline
\end{tabular}

Sumber : Imron Imron (2018)

6) Sintesis level 2 berdasarkan kerjasama tim
Tabel 11 Nilai Rata-rata Kerjasama Tim

\begin{tabular}{lcccc}
\hline Kriteria & Rudianto & $\begin{array}{c}\text { Chaerul } \\
\text { Umam }\end{array}$ & $\begin{array}{c}\text { Baso } \\
\text { Nurdiansyah }\end{array}$ & $\begin{array}{c}\text { Rata- } \\
\text { Rata }\end{array}$ \\
\hline Rudianto & 0,41 & 0,51 & 0,34 & 0,42 \\
\hline $\begin{array}{l}\text { Chaerul } \\
\text { Umam }\end{array}$ & 0,19 & 0,24 & 0,32 & 0,25 \\
\hline $\begin{array}{l}\text { Baso } \\
\text { Nurdiansyah }\end{array}$ & 0,40 & 0,25 & 0,34 & 0,33 \\
\hline & & & Eigen Vector & 1,00 \\
\hline $\begin{array}{l}\text { Sumber : Imron Imron (2018) } \\
\text { n }\end{array}$ & & &
\end{tabular}

\section{Mengukur Konsistensi}

Hitung Consistency Index (CI) dengan rumus:

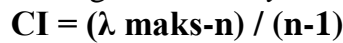

Hitung Rasio Konsistensi / Consistency Ratio (CR) dengan rumus:

CR = CI/IR
a) Konsistensi Level 1 Berdasarkan Kriteria Utama

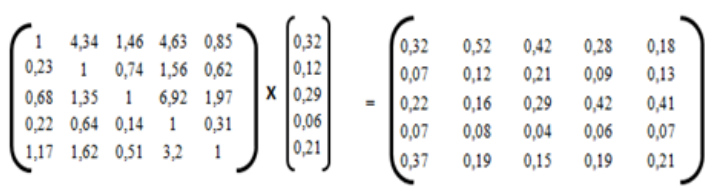

$$
\begin{aligned}
& =\left(\begin{array}{c}
1.72 \\
0.63 \\
1.5 \\
0.31 \\
1.12
\end{array}\right), \quad\left[\begin{array}{l}
0.32 \\
0.12 \\
0.29 \\
0.06 \\
0.21
\end{array}\right)=\left(\begin{array}{c}
5.38 \\
5.27 \\
5.17 \\
5.22 \\
5.33
\end{array}\right) \\
& \lambda \text { maksimal }=(5,38+5,27+5,17+5,22+5,33) / 5=5,27 \\
& \mathrm{CI}=(5,27-5) /(5-1)=0,07 \\
& \text { CR } \\
& =0,07 / 1,12=0,06
\end{aligned}
$$

b) Konsistensi Level 2 Berdasarkan Kriteria Penjualan

$$
\begin{aligned}
& \left(\begin{array}{ccc}
1 & 4,49 & 4,59 \\
0,22 & 1 & 0,81 \\
0,22 & 1,24 & 1
\end{array}\right) \times\left(\begin{array}{l}
0,69 \\
0,14 \\
0,16
\end{array}\right)=\left(\begin{array}{lll}
0,69 & 0,63 & 0,73 \\
0,15 & 0,14 & 0,13 \\
0,15 & 0,17 & 0,16
\end{array}\right) \\
& =\left(\begin{array}{l}
2,05 \\
0,42 \\
0,49
\end{array}\right) / \quad\left(\begin{array}{l}
0,69 \\
0,14 \\
0,16
\end{array}\right)=\left(\begin{array}{l}
2,98 \\
3,01 \\
3,03
\end{array}\right) \\
& \lambda \text { makssimal }=(2,98+3,01+3,03) / 3=3,006 \\
& \text { CI } \quad=(3,006-3) /(3-1)=0,003 \\
& C R \quad=0,003 / 0,58=0,005
\end{aligned}
$$

c) Konsistensi Level 2 Berdasarkan Kriteria Absensi 


$$
\begin{aligned}
& \left(\begin{array}{ccc}
1 & 2,54 & 1,58 \\
0,39 & 1 & 0,83 \\
0,63 & 1,2 & 1
\end{array}\right) \times\left(\begin{array}{l}
0,5 \\
0,22 \\
0,29
\end{array}\right)=\left(\begin{array}{lll}
0,5 & 0,56 & 0,46 \\
0,2 & 0,22 & 0,24 \\
0,32 & 0,26 & 0,29
\end{array}\right) \\
& \left(\begin{array}{r}
1.72 \\
0.63 \\
1.5 \\
0.31 \\
1.12
\end{array}\right) / \quad\left(\begin{array}{l}
0.32 \\
0.12 \\
0.29 \\
0.06 \\
0.21
\end{array}\right)=\left(\begin{array}{l}
5.38 \\
5.27 \\
5.17 \\
5.22 \\
5.33
\end{array}\right) \\
& \lambda \text { maksimal }=(3,03+2,98+3) / 3=3,004 \\
& \mathrm{CI}=(3.004-3) /(3-1)=0,002 \\
& \mathrm{CR}=0,002 / 0,58=0,003
\end{aligned}
$$

\section{d) Konsistensi Level 2 Berdasarkan Kriteria} Attitude

$$
\begin{aligned}
& \left.\left(\begin{array}{ccc}
1 & 3 & 1,55 \\
0,33 & 1 & 0,62 \\
0,64 & 1,62 & 1
\end{array}\right) \times \quad \begin{array}{l}
0,51 \\
0,18 \\
0,31
\end{array}\right)=\left(\begin{array}{lll}
0,51 & 0,54 & 0,48 \\
0,17 & 0,18 & 0,19 \\
0,33 & 0,29 & 0,31
\end{array}\right) \\
& =\left(\begin{array}{c}
1,53 \\
0,54 \\
0,93
\end{array}\right) /\left(\begin{array}{c}
0,51 \\
0,18 \\
0,31
\end{array}\right)=\left(\begin{array}{c}
3 \\
3 \\
2,99
\end{array}\right) \\
& \lambda \text { maksimal }=(3+3+2,99) / 3=2,999 \\
& \mathrm{CI}=(2,292-3) /(3-1)=-0,0005 \\
& \mathrm{CR} \quad=-0,0005 / 0,58=-0,0008
\end{aligned}
$$

e) Konsistensi Level 2 Berdasarkan Kriteria Penampilan

$$
\begin{aligned}
& \left(\begin{array}{ccc}
1 & 1,47 & 0,5 \\
0,68 & 1 & 0,38 \\
1,64 & 2,65 & 1
\end{array}\right) \times \quad\left(\begin{array}{l}
0,28 \\
0,2 \\
0,51
\end{array}\right)=\left(\begin{array}{lll}
0,28 & 0,29 & 0,26 \\
0,19 & 0,2 & 0,19 \\
0,46 & 0,53 & 0,51
\end{array}\right) \\
& =\left(\begin{array}{l}
0,83 \\
0,58 \\
1,5
\end{array}\right),\left(\begin{array}{l}
0,28 \\
0,2 \\
0,51
\end{array}\right)=\left(\begin{array}{l}
2,98 \\
2,92 \\
2,94
\end{array}\right) \text {. } \\
& \lambda \text { maksimal }=(2,96+2,92+2,94) / 3=2,94 \\
& \text { CI }=(2,94-3) /(3-1)=-0,03 \\
& \text { CR } \quad=-0,03 / 0,58=-0,05
\end{aligned}
$$

\section{f) Konsistensi Level 2 Berdasarkan Kriteria Kerjasama Tim}

$$
\begin{aligned}
& \left(\begin{array}{ccc}
1 & 2,13 & 1,01 \\
0,47 & 1 & 0,95 \\
0,99 & 1,05 & 1
\end{array}\right) \times\left(\begin{array}{l}
0,42 \\
0,25 \\
0,33
\end{array}\right)=\left(\begin{array}{ccc}
0,4 & 0,53 & 0,33 \\
0,2 & 0,25 & 0,31 \\
0,4 & 0,26 & 0,33
\end{array}\right) \\
& =\left(\begin{array}{l}
1,29 \\
0,76 \\
1,01
\end{array}\right) /\left(\begin{array}{l}
0,42 \\
0,25 \\
0,33
\end{array}\right)=\left(\begin{array}{l}
3,04 \\
3,04 \\
3,00
\end{array}\right) \\
& \lambda \text { maksimal }=(3,06+3,04+3,06) / 3=3,05 \\
& \text { CI } \quad=(3.05-3) /(3-1)=0,03 \\
& \mathrm{CR} \quad=0,03 / 0,58=0,05
\end{aligned}
$$

Setelah melakukan proses pengukuran konsistensi kegiatan selanjutnya adalah melakukan sistesa global untuk pengambilan keputusannya. Prosedurnya adalah sebagai berikut:

1. Mengalikan gabungan vector eigen pada level 2 (level alternatif keputusan) dengan vector eigen pada level 1 (level kriteria) dan hasil operasi perkalian tersebut selanjutnya disebut sebagai "vector eigen keputusan".

2. Keputusan yang diambil adalah keputusan yang mempunyai nilai yang paling benar.

$$
\begin{aligned}
& \left(\begin{array}{lllll}
0,69 & 0,5 & 0,51 & 0,28 & 0,42 \\
0,14 & 0,22 & 0,18 & 0,2 & 0,25 \\
0,16 & 0,29 & 0,31 & 0,51 & 0,33
\end{array}\right) \times\left(\begin{array}{l}
0,32 \\
0,12 \\
0,29 \\
0,06 \\
0,21
\end{array}\right)=\left(\begin{array}{lllll}
0,22 & 0,06 & 0,15 & 0,02 & 0,09 \\
0,04 & 0,03 & 0,05 & 0,01 & 0,05 \\
0,05 & 0,03 & 0,09 & 0,03 & 0,07
\end{array}\right) \\
& =\left(\begin{array}{l}
0,53 \\
0,19 \\
0,28
\end{array}\right)
\end{aligned}
$$

\section{E. Hasil}

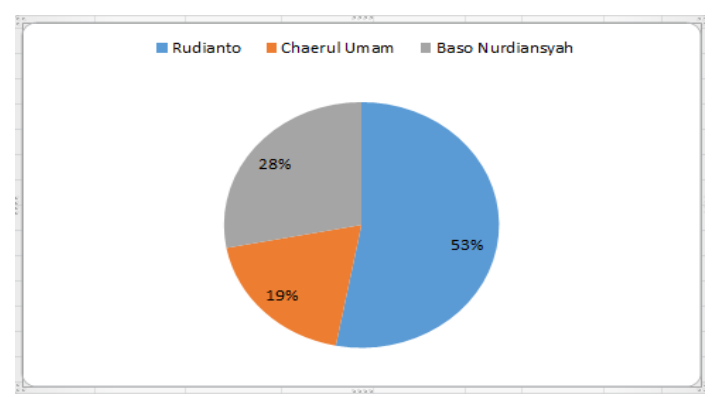

Sumber : Imron Imron (2018)

Gambar 3

Presentase Vector Eigen Keputusan 


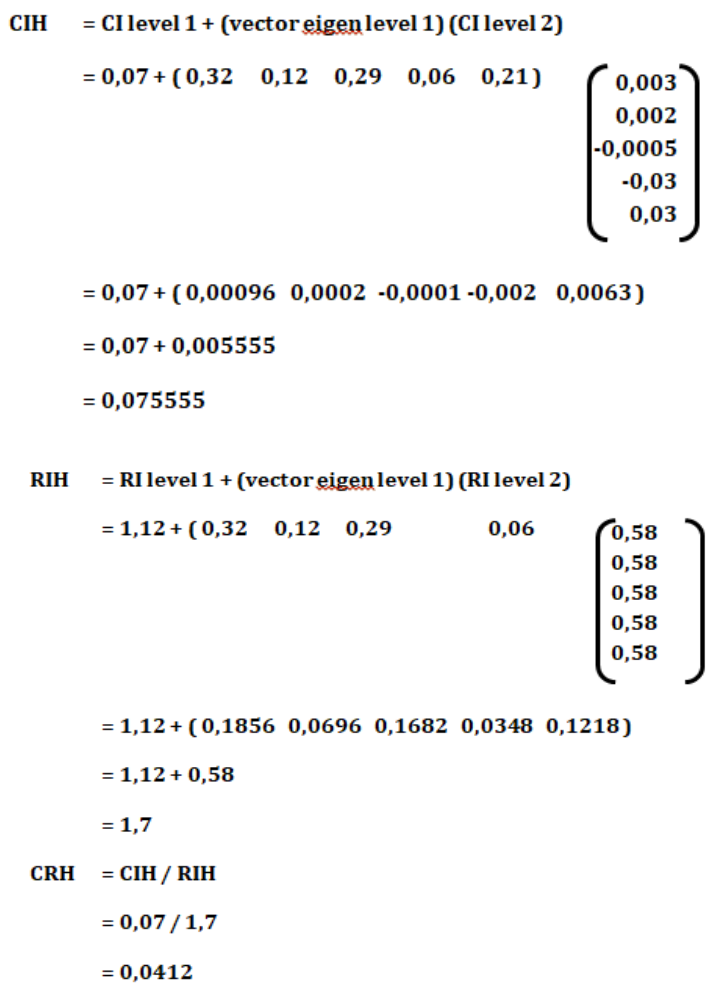

Dari perhitungan diatas diperoleh nilai $\mathrm{CRH}$ kurang dari 0.1 atau kurang dari $10 \%$ maka hirarki secara keseluruhan bersifat konsisten, sehingga kesimpulan yang diperoleh dapat diterima, artinya keputusan yang ditetapkan dapat diandalkan. Maka, kesimpulan yang didapatkan dari hasil yang telah diperoleh sudah sesuai terhadap hasil hipotesis.

\section{F. Pengolahan Data Menggunakan Expert Choice 1) Kriteria Utama}

\begin{tabular}{|l|l|l|l|l|l|}
\hline & PENJUALAN & ABSENSI & ATITUDE & PENAMPILA KERJASAMA TIM \\
\hline PENJUALAN & & 4,34284 & 1,46311 & 4,63041 & 1,17309 \\
\hline ABSENSI & & & 1,35156 & 1,55070 & 1,61794 \\
\hline ATITUDE & & & & 6,92408 & 1,96897 \\
\hline PENAMPILAN & & & & & 3,19864 \\
\hline KERJASAMA TIM & Incon: 0,06 & & & & \\
\hline
\end{tabular}

Sumber : Imron Imron (2018)

Gambar 4.

Input Kriteria Utama Pada Software Expert Choice

Dibawah ini adalah grafik vector eigen terhadap kriteria utama.

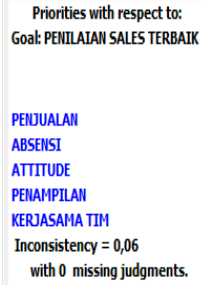

Sumber : Imron Imron (2018)

Gambar 5. Grafik Hasil Input Data Kriteria Utama Pemilihan Sales Terbaik

\begin{tabular}{|l|c|r|r|}
\hline & RUDIANTO & CHAERUL UMAM & BASO NURDIANSYAH \\
\hline RUDIANTO & & 4,49064 & 4,58843 \\
\hline CHAERUL UMAM & & & 1,2353 \\
\hline BASO NURDIANSYAH & InCON: 0,01 & & \\
\hline
\end{tabular}

Sumber : Imron Imron (2018)

Gambar 6. Input Kriteria Penjualan Pada Software Expert Choice

Dibawah ini adalah grafik vector eigen terhadap kriteria penjualan

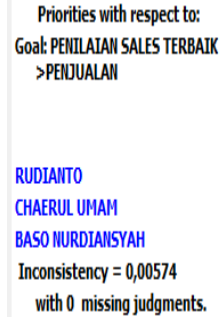

Sumber : Imron Imron (2018)

Gambar 7. Grafik Hasil Input Data Kriteria Penjualan Pada Pemilihan Sales Terbaik

\section{3) Kriteria Absensi}

\begin{tabular}{|c|c|c|c|}
\hline & RUDIANTO & CHAERULL UMAM & BASO NURDIANSYAH \\
\hline RUDIANTO & & 2,53678 & 1,57547 \\
\hline CHAERUL UMAM & & & 1,20379 \\
\hline BASO NURDIANSYAH & Incon: 0,01 & & \\
\hline
\end{tabular}

Sumber : Imron Imron (2018)

Gambar 8 Input Kriteria Absensi Pada Software Expert Choice

Dibawah ini adalah grafik vector eigen terhadap kriteria absensi

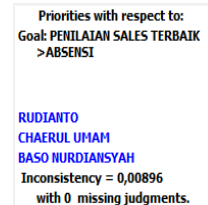

Sumber : Imron Imron (2018)

Gambar 9. Grafik Hasil Input Data Kriteria Absensi Pada Pemilihan Sales Terbaik

\section{4) Kriteria Attitude}

\begin{tabular}{|l|l|r|r|}
\hline & RUDIANTO & CHAERUL UMAM & BASO NURDIANSYAH \\
\hline RUDIANTO & & 3,00461 & 1,5513 \\
\hline CHAERUL UMAM & & & 1,61794 \\
\hline BASO NURDIANSYAH & InCON: 0,00 & & \\
\hline
\end{tabular}

Sumber : Imron Imron (2018)

Gambar 10 Input Kriteria Attitude Pada Software Expert Choice

\section{2) Kriteria Penjualan}


Dibawah ini adalah grafik vector eigen terhadap kriteria attitude

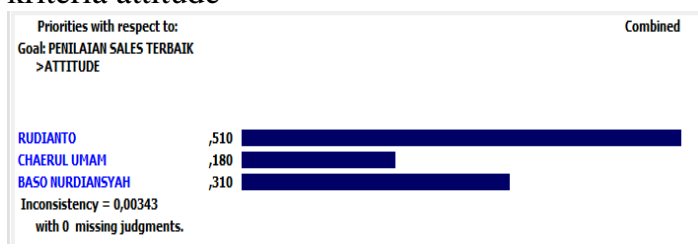

Sumber : Imron Imron (2018)

Gambar 11. Grafik Hasil Input Data Kriteria Attitude Pada Pemilihan Sales Terbaik

\section{5) Kriteria Penampilan}

\begin{tabular}{|l|r|r|r|}
\hline \hline & RUDIANTO & CHAERUL UMAM BASO NURDIANSYAH \\
\hline RUDIANTO & & 1,47204 & 2,00981 \\
\hline CHAERUL UMAM & & & 2,64642 \\
\hline BASO NURDIANSYAH & InCON: 0,00 & & \\
\hline
\end{tabular}

Sumber : Imron Imron (2018)

Gambar 12 Input Kriteria Penampilan Pada Software Expert Choice

Dibawah ini adalah grafik vector eigen terhadap kriteria penampilan
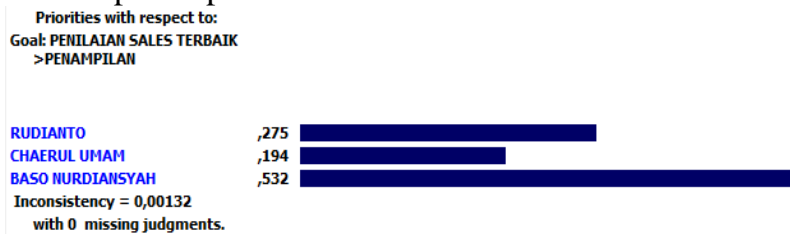

Sumber : Imron Imron (2018)

Gambar 13 Grafik Hasil Input Data Kriteria

Penampilan Pada Pemilihan Sales Terbaik

\section{6) Kriteria Kerjasama Tim}

\begin{tabular}{|lrrr|}
\hline & RUDIANTO & CHAERUL UMAM BASO NURDIANSYAH \\
\hline RUDIANTO & & 2,13042 & 1,01096 \\
\hline CHAERUL UMAM & & & 1,04879 \\
\hline BASO NURDIANSYAH & InCOn: 0,05 & & \\
\hline
\end{tabular}

Sumber : Imron Imron (2018)

Gambar 3.14 Input Kriteria Kerjasama Tim Pada Software Expert Choice

Dibawah ini adalah grafik vector eigen terhadap kriteria kerjasama tim

Priorities with respect to:

GOal: PENILIIAN SALES TERBAIX

Combined

RUDIANTO

CHAERUL UMAM

BASO NURDIANSYAH

Inconsistency $=0,05$

Sumber : Imron Imron (2018)

Gambar 15 Grafik Hasil Input Data Kriteria

Kerjasama Tim Pada Pemilihan Sales Terbaik

\section{7) Synthesize}

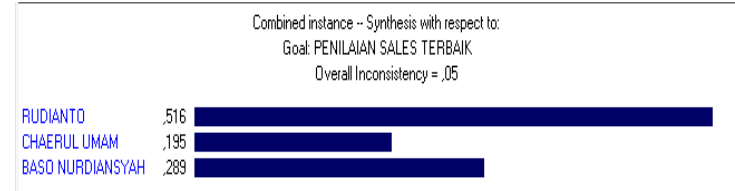

Sumber : Imron Imron (2018)

Gambar 16 Grafik Synthesis With Respect To Goal : Pemilihan Sales Terbaik

\section{KESIMPULAN}

Dari hasil pengolahan data serta analisis pada bab sebelumnya maka dapat diambil beberapa kesimpulan sebagai berikut :

1. Hasil responden menyatakan bahwa alternatif pemilihan sales terbaik yang paling sesuai sebagai berikut : Rudianto dengan nilai sebesar $53 \%$, Baso Nurdiansyah dengan nilai sebesar $28 \%$ dan Chaerul Umam dengan nilai sebesar $19 \%$

2. Peringkat kriteria yang perlu diperhatikan dalam pemilihan sales terbaik sebagai berikut : Penjualan, attitude, kerjasama tim, absensi, penampilan.

3. Dengan melakukan pengujian dan dan perhitungan sesuai proses metode AHP secara manual dan perhitungan menggunakan software expert choice 11 maka diketahui bahwa hasil yang diperoleh tidak jauh berbeda, dengan demikian secara umum perhitungan secara manual sudah benar dan software telah bekerja dengan baik sesuai yang diharapkan.

4. Metode Analytical Hierarchy Process dapat digunakan untuk sistem pendukung keputusan pemilihan sales terbaik dengan menentukan tujuan, kriteria dan alternatif yang akan digunakan dengan membentuk sebuah hierarki, sehingga dapat membantu dalam melihat permasalahan yang dihadapi secara lebih terperinci.

5. Dalam merancang sistem pendukung keputusan dengan metode Analytical Hierarchy Process haruslah mengikuti tahapan-tahapan yang sesuai dengan metode dan perhitungan yang teliti agar data yang dihasilkan dapat diterima dan keputusan yang dihasilkan dapat diandalkan.

6. Penelitian ini menggunakan satu metode yaitu Analytical Hierarchy Process dan dengan jumlah responden yang cukup sedikit yaitu 16 responden yang berkompeten dan hasil pengujian dan perhitungan dapat dipercaya..

\section{REFERENSI}

Aisyah, Nurul dan Nita Merlina. 2013. Decision Support System Penyaluran Kredit Usaha Rakyat ( KUR ) Mikro Menggunakan Metode Analytical Hierarchy Process ( Ahp ). Jurnal Pilar Nusa Mandiri. Vol. IX No. 1, Maret 2013. Diambil dari: http://ejournal.nusamandiri.ac.id/ejurnal/ind 
ex.php/pilar/article/view/12/10

Amalia, Rizky Multi dan Dwi Yuni Utami. 2018. Pemberian Reward Berdasarkan Penilaian Kinerja Karyawan Dengan Metode AHP Pada PT. Anugerah Protecindo. Jurnal Ilmu Pengetahuan dan Teknologi Komputer. Vol. 3, No. 2, Februari 2018. Diambil dari : http://ejournal.nusamandiri.ac.id/ejurnal/ind ex.php/jitk/article/view/572/402

Anggraini dan Mulyadi. 2018. Pengarug Latar Belakang Pendidikan Orang Tua Terhadap Kemampuan Berbicara Bahasa Inggris di SMK. Jurnal Ilmu Pengetahuan dan Teknologi Komputer. Vol. 3, No, 2 , Februari 2018. Diambil dari : http://ejournal.nusamandiri.ac.id/ejurnal/ind ex.php/jitk/article/view/670

Darmanto, Eko, Noor Latifah dan Nanik Susanti. 2014. Penerapan Metode AHP (Analythic Hierarchy Process) Untuk Menentukan Kualitas Gula Tumbu. ISSN : 2252-4983. Jurnal SIMETRIS. Vol. 5 No. 1, April 2014. Diambil dari

http://jurnal.umk.ac.id/index.php/simet/artic le/view/139/144

Indarti dan Denny Pribadi. 2017. Analytical Hierarchy Proses Sebagai Penunjang Sistem Pengambilan Keputusan Dalam Penilaian Pelayanan Pada TPU Wilayah Jakarta Utara. Jurnal Pilar Nusa Mandiri. Vol. 13, No. 2, September 2017. Diambil dari : http://ejournal.nusamandiri.ac.id/ejurnal/ind ex.php/pilar/article/view/544/377

Safitri, Kamalia, Fince Tinus Waruwu, Mesran. 2017. Sistem Pendukung Keputusan Pemilihan Karyawan Berprestasi Dengan menggunakan metode Analytical Hierarchy Process (Studi Kasus : PT. Capella Dinamik Nusantara Takengon). ISSN : 2548-8368. Media Informatika Budidarma Vol. 1, No. 1, Maret 2017. Diambil dari : http://ejurnal.stmik-

budidarma.ac.id/index.php/mib/article/view /317

Malik, Ahmaf Yusuf dan Tuti Haryanti. 2018. Penerapan Metode Analytical Hierarchy
Process (AHP) Untuk Sistem Pendukung Keputusan Pemilihan Program Keahlian Pada SMK Daarul Ulum Jakarta. Jurnal Pilar Nusa Mandiri. Vol. 14, No. 1, Maret 2018. Diambil dari

http://ejournal.nusamandiri.ac.id/ejurnal/ind ex.php/pilar/article/view/819

Pratiwi, Heni. 2016. Sistem Pendukung Keputusan. Yogyakarta: Deepublish

Saaty, Thomas L.The Analytic Network Process: Decision Making with Dependence and Feedback, 386 pp., RWS Publ., 2001. ISBN 0-9620317-9-8

Sanyoto, Gathot Pujo, Rani Irma Handayani dan Euis Widanengsih. 2017. Sistem Pendukung Keputusan Pemilihan Laptop Untuk Kebutuhan Operasional Dengan Metode AHP (Studi Kasis Direktorat Pembinaan Kursus dan Pelatihan Kemdikbud). Jurnal Pilar Nusa Mandiri. Vol. 13, No. 2, September 2017. Diambil dari : http://ejournal.nusamandiri.ac.id/ejurnal/ind ex.php/pilar/article/view/505/352

Sarifah Dan Nita Merlina. 2015. Sistem Penunjang Keputusan Pemilihan Handphone Menggunakan Metode Analytical Hierarchy Process. Jurnal Pilar Nusa Mandiri. Vol. XI, No. 1, Maret 2015. Diambil dari : http://ejournal.nusamandiri.ac.id/ejurnal/ind ex.php/pilar/article/view/141/128

Setiawan, Santoso. 2016. Sistem Pendukung Keputusan Pemilihan Kendaraan Dinas Pejabat Menggunakan Analytical Hierarchy Process. Jurnal Pilar Nusa Mandiri. Vol. XII, No. 2, September 2016. Diambil dari : http://ejournal.nusamandiri.ac.id/ejurnal/ind ex.php/pilar/article/view/178/154

\section{PROFIL PENULIS}

Imron, Lahir di Jakarta, 29 November 1981, berkarir sebagai dosen di Universitas BSI sejak tahun 2015. Menyelesaikan Pendidikan Formal Strata 1 dan Strata 2 pada STMIK Nusa Mandiri Jakarta. 